\title{
Effects of Ethanol on Combustion and Emissions of a Gasoline Engine Operating with Different Combustion Modes
}

\author{
Mohammed Moore Ojapah ${ }^{1,2}$, Hua Zhao ${ }^{1}$ and Yan Zhang ${ }^{1}$ \\ ${ }^{1}$ Centre for Advanced Powertrain and Fuels, College of Engineering, Design and Physical Sciences, Brunel \\ University London, UK \\ ${ }^{2}$ Mechanical Engineering Department_ Faculty of Engineering, University of Port Harcourt, Nigeria
}

\begin{abstract}
The introduction of fuel economy and CO2 emission legislations for passenger cars in many countries and regions has spurred the research and development of more efficient gasoline engines. The pumping loss at part-load operations is a major factor for the higher fuel consumption of spark ignition (SI) gasoline engines than the diesel engines. Various approaches have been identified to reduce the pumping loss at part-load operations, leading to improved fuel economy, including Early Intake Valve Closing (EIVC), Positive Valve Overlap (PVO) and Controlled Auto-Ignition (CAI) combustion. On the other hand, in order to reduce the $\mathrm{CO} 2$ emissions from the fossil fuel, ethanol produced from renewable resources is becoming widely used in the gasoline engine. In this paper, the performance, combustion and emissions were measured, analyzed and compared between gasoline and its mixture with ethanol (E15 and E85) at a typical part-load condition when a direct injection gasoline engine was operated with the CAI combustion by means of the negative valve overlap (NVO) and SI combustion by means of the intake throttled, EIVC and PVO. An electro hydraulic actuated camless system enabled the engine to be operated with CAI combustion and SI combustion of different valve timings and durations at the same load. The results showed that the CAI combustion reduces NOx emissions by more than 90\%. The PVO results in better mixture preparations and improved combustion efficiency and best fuel economy compared to all the other modes. The EIVC operation led to a moderate improvement in the fuel conversion efficiency over the throttled SI operation but it was characterised by the slowest combustion and worst $\mathrm{HC}$ and $\mathrm{CO}$ emissions. Fewer and smaller particles numbers were detected in EIVC using E0 and E15 fuel blends. Using ethanol blends reduces the knocking combustion in CAI modes by about 50\%. The use of E85 resulted in an increased number of particulate emissions in EIVC but increased ISFC in all the modes. The particulate emission results showed that soot is the dominant particle in the exhaust.
\end{abstract}

\section{Key Words}

EIVC, PVO, CAI, GDI, Ethanol, Gasoline Particulates

\section{Introduction}

With increasing concerns with CO2 emissions and increased fuel cost, automotive industries are researching and developing practical technologies to improve fuel economy and reduce tail-pipe emissions. As the dominant powerplant for passenger cars, the spark ignition (SI) engines are subjected to frequent part-load operations during a typical vehicle driving cycle, when they operate with lower efficiency due to the pumping losses that occur when the intake 
throttle is partially closed. In order to develop more efficient and cleaner gasoline engines, a number of new engine operating strategies in recent years have been proposed.

In order to minimize the pumping loss, variable valve actuation can be used to regulate the amount of air into the cylinder by varying the intake valve lift and duration [1]. The early intake valve closing (EIVC) is a technique where the intake valve is closed before BDC when the required quantity of air is admitted into the cylinder. The EIVC can be achieved by both reduced valve lift and duration with a low lift cam lobe using a mechanical variable valve actuation system or a shorter duration with a camless valve actuation system. Several studies have been performed on the effectiveness of EIVC to reduce fuel consumption. An early study by Kreuter et al. [2] suggested that a maximum valve lift of $2 \mathrm{~mm}$ or less could result in higher flow-in velocities even at low engine load and speed conditions. The resulting microturbulences in the region between the valve and valve seat effectively supports the mixture preparation and helps to compensate the reduction of in-cylinder turbulence which is principally associated with unthrottled load control by means of early intake valve closing. Vogel et al. [3] investigated the effect of EIVC on fuel consumption and pumping losses on a 4 cylinder gasoline engine fitted with a secondary valve assembly between the cylinder head and the original intake manifold of the engine. The aim was to implement EIVC with the secondary valve. This strategy enabled a $70 \%$ reduction in pumping loss and $4 \%$ improvement in fuel economy. Soderberg, F., and Johansson, B. [4] conducted experiments on a single cylinder of the five cylinder 2.5 liter Volvo B5254 engine. The engine was modified to use one of the cylinders for combustion and the other four cylinders were motored. The engine has no means of changing valve timing during operations, different camshafts were used. They recorded noticeable fuel consumption improvement at low-speed and low-load conditions. It was also reported that the EIVC resulted in poor combustion as a result of reduced in-cylinder turbulence, temperature, and reduced mixing through the inlet valve. Urata et al [5] manufactured engine equipped with newly developed hydraulic variable valve train (HVT), which can vary its intake-valve closing-timing freely. They reported a reduced pumping loss of $80 \%$ and $7 \%$ reduced fuel consumption. They observed lower incylinder compression temperature and increased combustion fluctuation under low load. More recently, Patel et al [6] reported that the EIVC could be used to improve part-load fuel efficiency in a direct-injection gasoline engine.

In addition, variable intake and exhaust valve timings can be used to reduce the pumping loss through internal exhaust gas recirculation (iEGR). This can be accomplished by the positive valve overlap (PVO), the negative valve overlap (NVO) and the exhaust gas re-breathing of intake and exhaust valves. In the case of PVO, the intake valve is opened early during the exhaust stroke and the exhaust valve is delayed into the intake stroke, thereby creating a positive valve overlap about low-pressure top dead centre (TDC). The NVO is achieved by closing the exhaust valve early and late opening of intake valve, thereby retaining hot residual gas in the cylinder. The exhaust-gas re-breathing strategy is accomplished by reopening of the exhaust valve during the intake stroke, or the second opening of the intake valve in the exhaust stroke. 
Another effective way to reduce part-load fuel consumption is the controlled auto-ignition (CAI) combustion operation [7]. One of the most effective and practical ways to achieve CAI combustion is through the negative valve overlap method, which involves the earlier closure of the exhaust valve to trap burned gases, and retarded intake-valve opening to control the amount of air into the cylinder. HCCI/CAI combustion was first demonstrated in internal combustion engines by Onishi et al [8] for use in two-stroke engines, through the use of hot residual gas retained in the cylinder. Since then a large number of studies of CAI from experimental and modelling point of view have been completed.

Allen and Law [9] were among the first to use an electro-hydraulic active valve train (AVT) to trap exhaust-gas residuals leading to spontaneous combustion of a stoichiometric air-fuel ratio. Numerous other investigators notably Koopmans et al. [10], Zhao et al. [11] and Wolters et al. [12], have demonstrated CAI combustion using variable-valve-timing (VVT) mechanisms to trap hot exhaust gas. In most investigations, advanced EVC and retarded intake valve opening (IVO) were used to trap hot exhaust gas. Subsequent mixing of the fuel and air with hot gas creates localised hot spots throughout the mixture. Compression further increases the mixture temperature leading to auto-ignition.

Various camshaft-based, mechanical, variable-valve-lift systems have been implemented in production engines. They range from the 2-step cam profile switching [13, 14] to continuous mechanical variable-lift mechanisms, such as BMW valvetronic and Fiat's multi-air valve actuation system. Such camshaft operated systems allow the valve lift and duration to be changed, although not independently. Fully Flexible Variable Valve Actuation (FFVVA) systems are capable of independent control over the valve lift, opening and closing timings, and duration. The FFVVA camless system can be either electromagnetic, electro-pneumatic or electrohydraulic and used to drive individual engine valves directly and independently [1524].

In the meantime, depleting reserves of fossil fuels and the increasing environmental pollution caused by burning of fossil fuels have prompted the fuel diversification to cleaner and renewable fuels. The use of ethanol as an alternative transportation fuel shows promise for several reasons. While ethanol can be produced from several types of biomass, it offers properties such as higher octane number, higher oxygen content and higher heat of evaporation than gasoline, which make it a most attractive alternative fuel, in particular for the direct injection gasoline engine [25].

Furthermore, direct injection gasoline engine have been developed recently because of their potential for better fuel economy and better performance, through unthrottled part-load operation and in particular the engine downsizing technology. However, due to the limited time available for complete fuel evaporation and the mixing of fuel and air mixture in a direct injection gasoline engine, locally fuel rich mixture or even liquid fuel can be present during the combustion process [26]. This can result in significant increase in THC, CO and Particulate Matter (PM) emissions from direct injection gasoline engines compared to the conventional port fuel injection gasoline engines [27, 28]. Several studies have been performed to understand the mechanism by which direct injection gasoline engine generates 
gaseous and particulate emissions [29-33] but very little research was done on particulate matter emissions from different operational modes at the same engine load.

Amongst the previous studies, there is a lack of direct comparison between various operating strategies and alternative fuels. In this work, the performance, combustion process and emission were measured and compared between the intake throttled, EIVC, PVO and CAI operations with gasoline and its mixture with ethanol (E15 and E85). In addition, the number of particle emissions and particle size distributions were examined and compared between the four operational modes.

In this work, experiments were carried out in a direct injection gasoline engine during the throttled operation, EIVC, PVO, and the CAI combustion operations by means of an electrohydraulic VVA system. The effect of such operating modes on the gaseous and particulate emissions was also analysed by means of an Electrostatic Mobility Spectrometer (EMS) based particle sizer and Horiba exhaust-gas emission analysers. In particular, the addition of ethanol on the particulate emissions was studied and compared between these operating modes.

\section{Experimental Set Up}

All experiments were conducted in a single-cylinder engine research facility, as shown in Figure 1a. It comprises a single-cylinder direct-injection gasoline engine equipped with a electrohydraulic valve actuation system, a high-pressure hydraulic pack for the electrohydraulic actuators, an AC dynamometer, a supercharger unit, emission measurement and analysers, data logging and analysis system. A Denso double-slit injector was used and fuelinjection pressure was set to 100bar. An AVL supercharger system was connected to the intake system of the engine to supply compressed air at a preset boost pressure and temperature through a closed loop control of heaters and heat exchangers. A laminar air-flow meter was installed in the engine intake system to measure the intake mass-flow rate. Both the intake and exhaust pressures were measured by two piezo-resistive pressure-transducers.

The single-cylinder camless engine was coupled to an AC dynamometer for motored and firing operations. The engine is capable of 2- and 4-stroke cycle operations through the flexible electro-hydraulic actuated intake and exhaust valves. The engine has a bore of $81.6 \mathrm{~mm}$ and a stroke of $66.94 \mathrm{~mm}$. The engine speed range is $0-6500 \mathrm{rev} / \mathrm{min}$ in the 4 -stroke mode and up to 4000rpm in the 2-stroke mode. The engine details are given in Table 1.

The instantaneous relative air to fuel ratio, Lambda, was measured by a Bosch lambda sensor connected to a MOTEC lambda meter. A Horiba 7170DEGR gas-analyser system was used to measure the levels of carbon monoxide $(\mathrm{CO})$, carbon dioxide $\left(\mathrm{CO}_{2}\right)$, total unburnt hydrocarbons (THC), and nitrogen oxides (NOx) from the exhaust. 


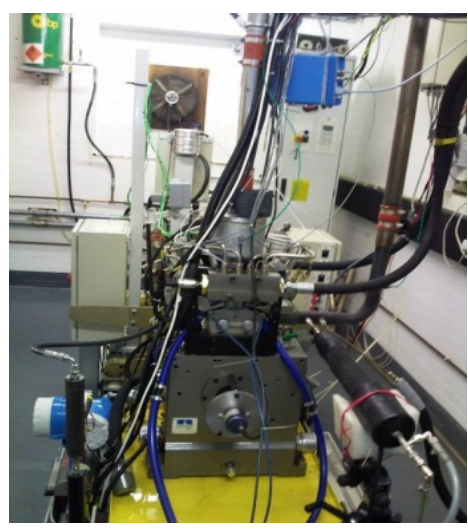

(a)

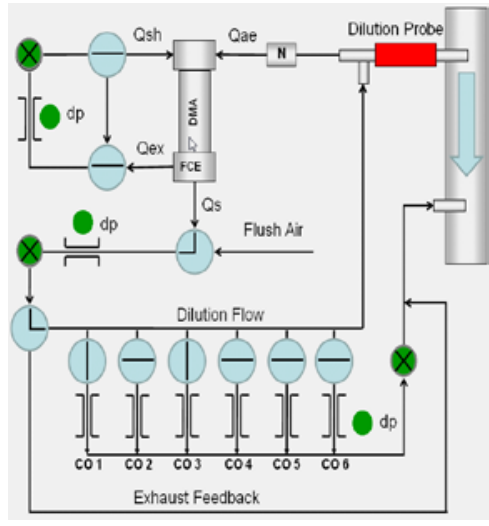

(b)

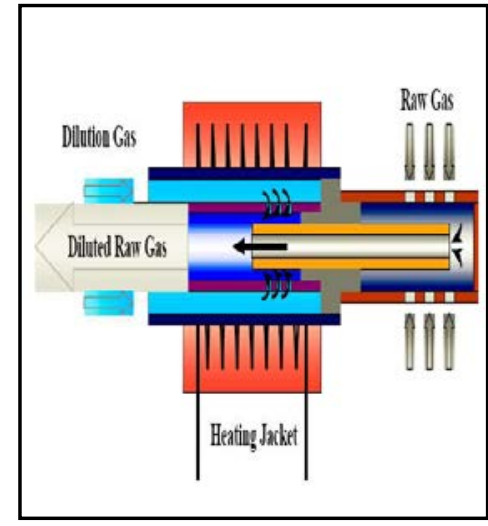

(c)

Figure 1: (a) single cylinder engine on the test bed; (b) schematic diagram of the EMS VIE system and (c) dilution probe for PM measurements

Table 1 Engine Specification

\begin{tabular}{|l|l|}
\hline Bore $\times$ Stroke & $81.6 \mathrm{~mm} \times 66.94 \mathrm{~mm}$ \\
\hline Compression ratio & $11.78: 1$ \\
\hline Combustion Chamber & Pent roof / 4 valves \\
\hline Valve train & Electro-hydraulic actuation \\
\hline Fuel Injection & Direct Injection \\
\hline Fuel & Standard Gasoline (RON 95), E15 and E85 \\
\hline Air/Fuel Ratio & Stoichiometric or lean \\
\hline Intake Temperature & 25 degree Celsius \\
\hline
\end{tabular}

In parallel, exhaust gas was sampled from the exhaust pipe for gaseous and particulate emission measurements. The exhaust-particle measurement in this study was carried out with an Electrostatic Mobility Spectrometer EMS VIE. Samples were taken 150mm downstream of the exhaust valves. The EMS is an automated system for the size classification and size analysis of airborne particles within the size range of 5 to $700 \mathrm{~nm}$, as shown in Figure 1b. The size separation of particles is based on the principle of electrical mobility. The electrical mobility of a particle determines the drift velocity of a charged particle under the influence of an electrical field. The Differential Mobility Analyser, DMA, within the EMS is used for this purpose. Within the DMA the particles are classified according to their electrical mobility, gas-flow velocity, geometry of the DMA, and the strength of the electric field. The strength of the electric field is varied by changing the voltage between the electrodes of the DMA. The sample from the exhaust of the engine was taken with the dilution probe for sampling of high-temperature and high-concentration aerosols in the exhaust duct. To avoid alteration of 
the aerosols in the raw gas, the dilution had to be performed as close to the sampling position as possible. The raw gas was diluted about 30-40 millimetres from the centre of the sampling probe shown in Figure 1(c). A dilution ratio of 100 was used in this test, the diluted raw gas passed through a charger or neutraliser to establish a well define distribution of electrical charges on the particles before being fed into the DMA. After classification, the concentration of the particles in the output-sample flow was determined by the Faraday Cup Electrometer FCE.

Typically it takes up to four minutes for a single-sample reading of particle size measurement by the EMS. The data can be displayed on-line and then converted into Excel format for postprocessing and analysis of the particle-size distribution as a function of the engine operating conditions and variables being investigated.

The particulate distribution was obtained from the number distribution. The values are unlikely to be universally applicable and as such, the mass distribution reported is comparative only. The particulate density was assumed to be $1.0 \mathrm{~g} / \mathrm{m}^{3}$.

\section{Engine Operating Conditions}

Because of the flexibility of the camless system and engine control software, four engine operational modes were achieved through different combinations of valve timings and durations. Figures 2 to 5 show the valve timings and injection timings used in different operational modes.

\section{Mode 1: 4-Stroke Throttled Controlled SI Mode}

This is the conventional spark-ignition mode used in the production gasoline engine shown in Figure 2a and the corresponding pressure volume diagram in $2 \mathrm{~b}$. Engine load is controlled by the throttle opening, and its combustion process is initialized by the spark discharge followed by flame propagation. The engine was operated in this mode to obtain the baseline data. At part load, the partially closed throttle results in a significant increase in the pumping loss, the main cause for the poor fuel economy of current SI gasoline engines. In this engine operational mode, fuel was injected earlier in the intake stroke to obtain a homogeneous mixture. To prevent wetting the piston top, injection-timing used in this mode was set to 412degCA ATDC. 


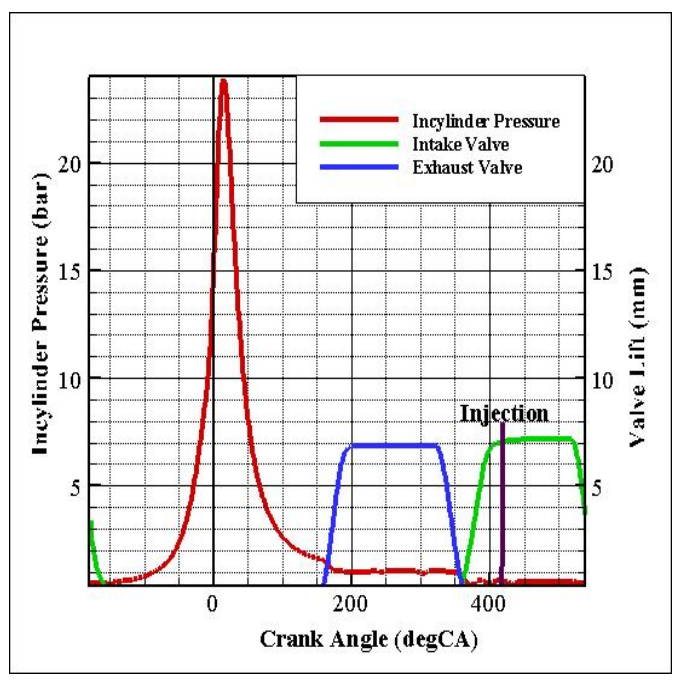

(a)

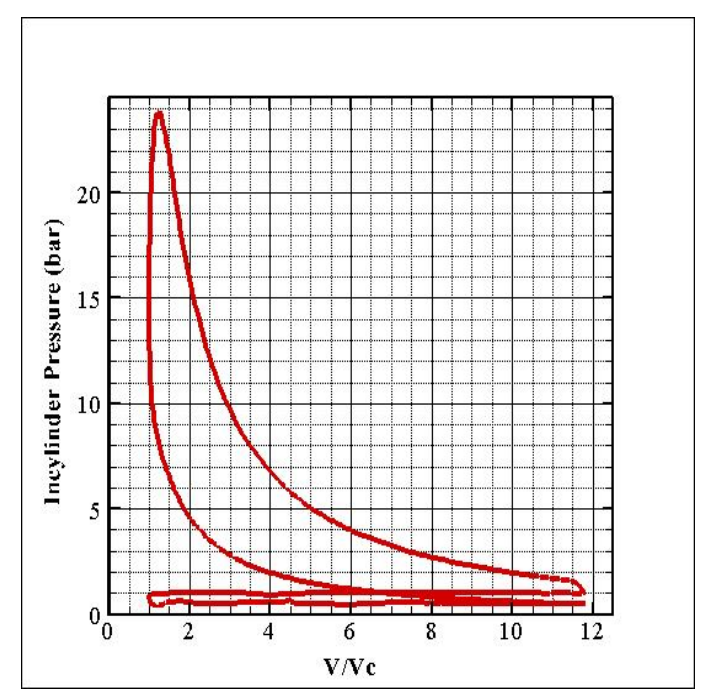

(b)

\section{Figure 2 Throttled SI (a) Valve and Injection timing, (b) P-V Diagram}

\section{Mode 2: 4-Stroke Intake Valve Throttled SI Mode}

This combustion mode is shown in Figure 3a and the pressure volume diagram is shown in Figure 3b. In order to reduce the pumping loss caused by the partially closed intake-throttle at part load, intake-valve opening duration and lift can be used to regulate the amount of air into the cylinder with wide open throttle (WOT). In this work, the intake-valve opening (IVO) was fixed at standard timing and the intake-valve closing (IVC) was varied to throttle the intake air-flow, the exhaust valve lift was set to $5 \mathrm{~mm}$ and the intake lift was reduced to $2 \mathrm{~mm}$ in order to simulate what could be achieved with a mechanical camshaft, start of injection was set to 412degCA ATDC.

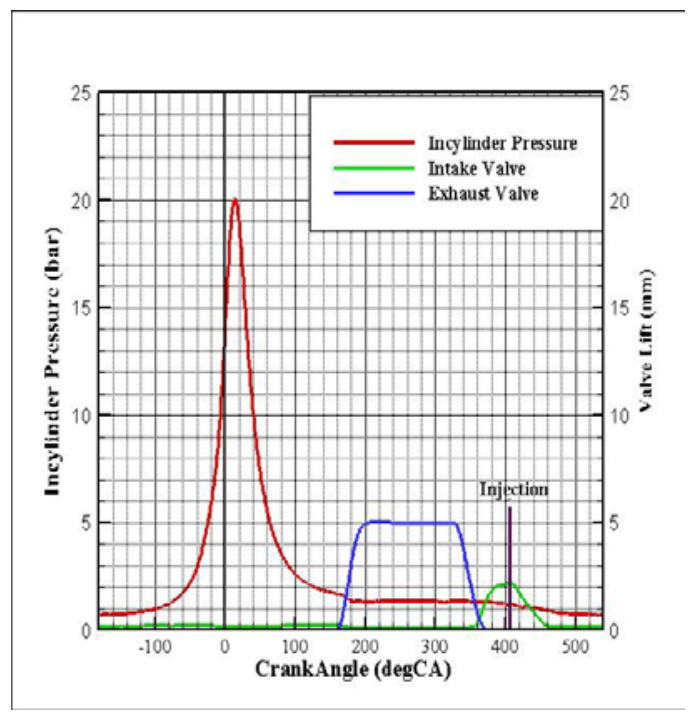

(a)

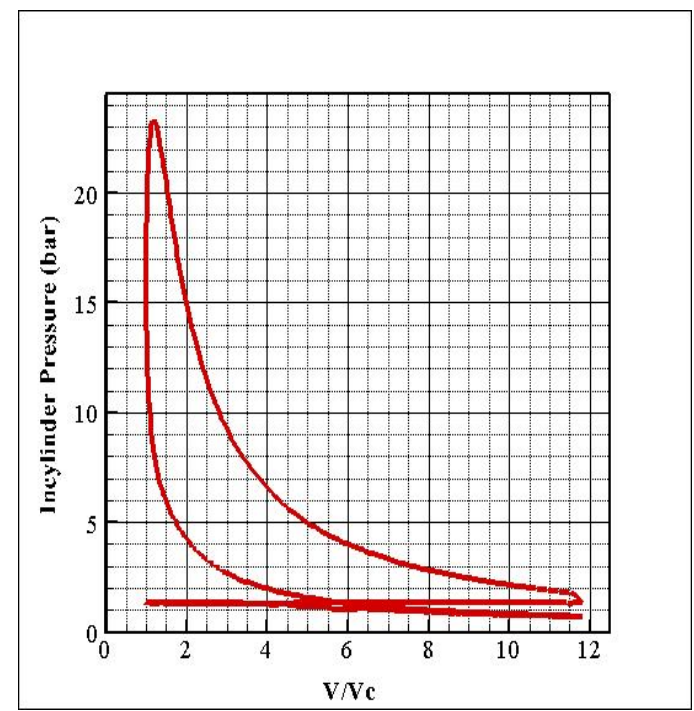

(b)

Figure 3 The EIVC SI (a) Valve and Injection Timing, (b) P-V Diagram 


\section{Mode 3: 4-Stroke Positive Valve Overlap SI Mode}

In this case IVO takes place before TDC and EVC after TDC to create a positive overlap between the intake and exhaust-valve opening periods. This combustion mode is shown in Figure $4 \mathrm{a}$ and the pressure volume diagram is shown in Figure $4 \mathrm{~b}$. As the intake-valves open in the exhaust stroke, a portion of exhaust-gas enters the intake port and is sucked back into the cylinder in the intake stroke. The exhaust valves close after TDC so that some exhaust gas is also sucked back into the cylinder. In this work, the exhaust-valve lift was maintained at $7.2 \mathrm{~mm}$ and the intake-valve lift was reduced to $3 \mathrm{~mm}$ to avoid any contact between the piston and valves at TDC during the gas exchange.. The fuel injection was set to 412degCA ATDC.

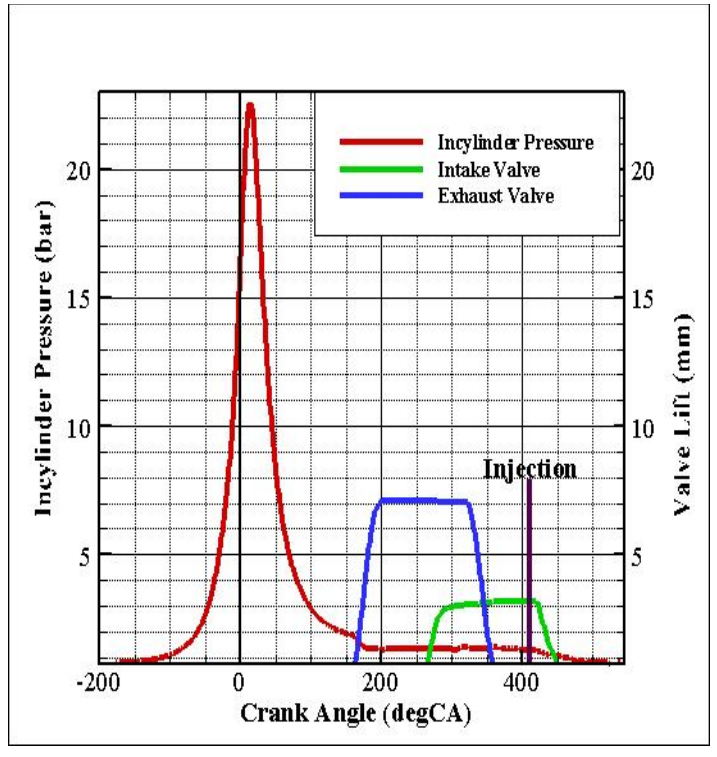

(a)



(b)

\section{Figure 4 The PVO SI (a) Valve and Injection Timing, (b) P-V Diagram}

\section{Mode 4: 4-Stroke Negative Valve Overlap CAI Mode}

Another way to obtain internal EGR is to trap a portion of the burnt gas in the cylinder by earlier closing of the exhaust valves. The combustion mode is shown in Figure 5(a) and the pressure volume diagram is shown in Figure 5(b). To minimise the backflow, the intake valves open later. The intake- and exhaust-valve lifts were maintained at $7.2 \mathrm{~mm}$.Then a negative valve overlap period is formed and the residuals are recompressed around the gasexchange near TDC. In this case, the intake air-flow rate is dependent on the amount of trapped residuals, which can be controlled by varying the exhaust-valve closing. This allows the throttle to be kept wide open and reduce pumping loss. As the exhaust valve closes earlier, the fuel-injection timing can be advanced into the exhaust stroke for better evaporation and mixing. In this work, the fuel was injected at 280degCA ATDC. 


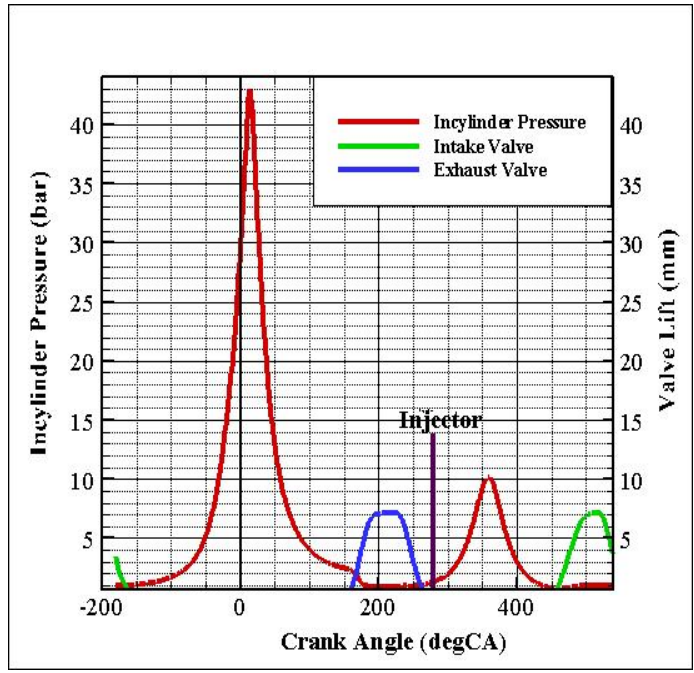

(a)

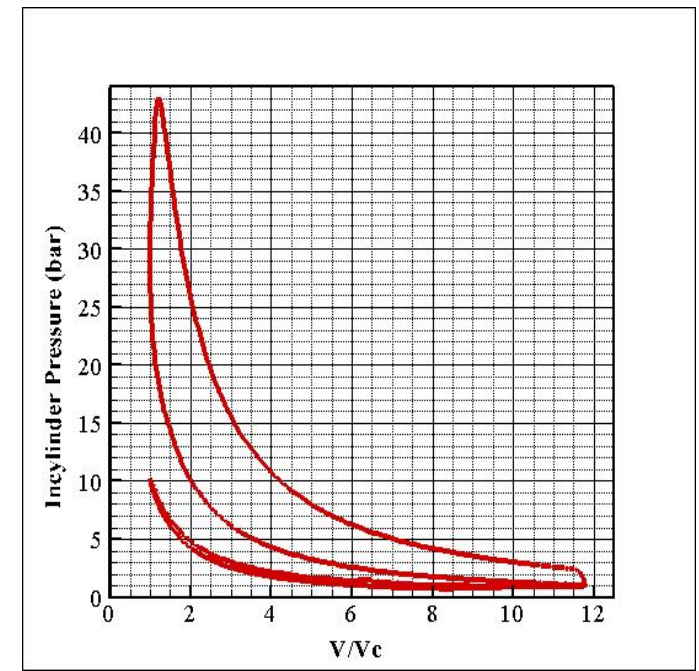

(b)

Figure 5 The CAI (NVO) (a) Valve and Injection Timing, (b) P-V Diagram

\section{Results and Discussions}

\section{Comparisons of Throttled SI, EIVC, PVO and CAI combustion}

In order to compare the results in different operation modes, the engine was run at a typical operational condition of 1500rpm and 3.2bar IMEP_net and lambda 1.0. The ignition timing was set to the Minimum Ignition advance for Best Torque (MBT). Ethanol had a faster flame speed than gasoline therefore the ignition timing of ethanol was retarded. This net IMEP used was equivalent to that generated in a suitable multi-cylinder production engine at a reference brake load of 2.62bar BMEP at 1500rpm. The oil and coolant temperatures were held at $80^{\circ} \mathrm{C}$. In investigating the effect of ethanol content, the experiment was performed for E0, E15, and E85 (corresponding to pure gasoline, 15\% and 85\% ethanol by volume in the fuel respectively).

The particle size distribution and the effect of ethanol on particle number (PN) and particle mass (PM) from different combustion modes were analysed and displayed with the $\mathrm{x}$-axis as the particle diameters, equally spaced on a log scale from $2.5 \mathrm{~nm}$ up to $500 \mathrm{~nm}$, and the PN concentration on the $y$-axis as $\mathrm{dN} / \mathrm{d} \ln \mathrm{D}\left(\# / \mathrm{cm}^{3}\right)$.

\section{Combustion Analysis}

Figure 6 shows and compares the combustion characteristics of the four operation modes with different fuel blends. As shown in Figure 6(a), the maximum pressure rise rate during the CAI combustion of gasoline was 5 bar/CA, which was 5 times higher than the throttled and unthrottled SI modes. With the presence of ethanol, the rate of pressure rise of CAI combustion with E15 and E85 was reduced below 1.4 bar/CA. As shown in Figure 6(b), the MBT was most advanced in the PVO operation amongst SI modes due to the slower turbulent velocities as reported in [34, 35], which is evident by the corresponding heat release rate curves in Figure 6(e). In addition, it can be seen that the CAI combustion which was 
autoignited was characterized by the most earlier combustion phasing (CA50) (Figure 6(c)) and the fastest combustion due to simultaneous burning of the cylinder charge. The combustion duration (Figure 6(d)) increased in the order of CAI, throttled SI, EIVC, to the PVO for all the fuels. In the PVO, the internal EGR resulted in the slower combustion speed. In the case of EIVC, the slower burning process is likely to be caused by decreased turbulence and the lower end of compression temperature. The addition of ethanol extended the duration of CAI combustion by about 25-30 crank angles but had little effect on the combustion duration in the throttled SI operation. In the EIVC and the PVO combustion modes, the use of ethanol blends led to increased combustion duration, which in turn led to higher exhaust temperatures shown in Figure 6(f) with the largest increase in CAI.

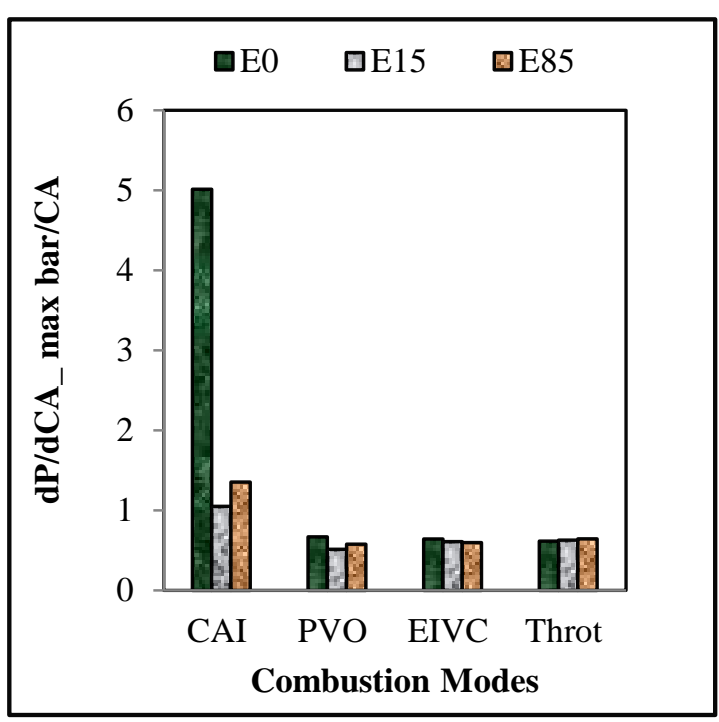

(a) Max Pressure rise rate

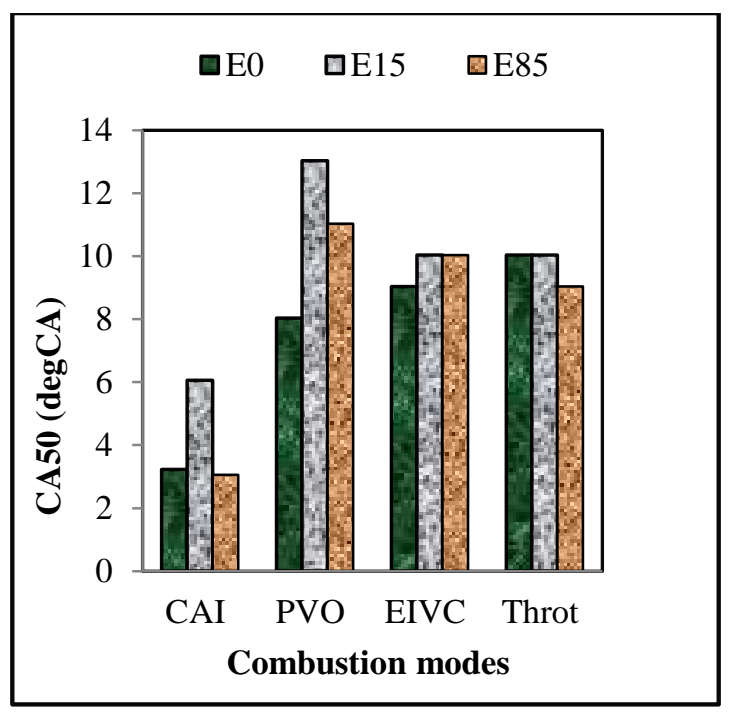

(c) Comb Phasing CA50 (degCA ATDC)

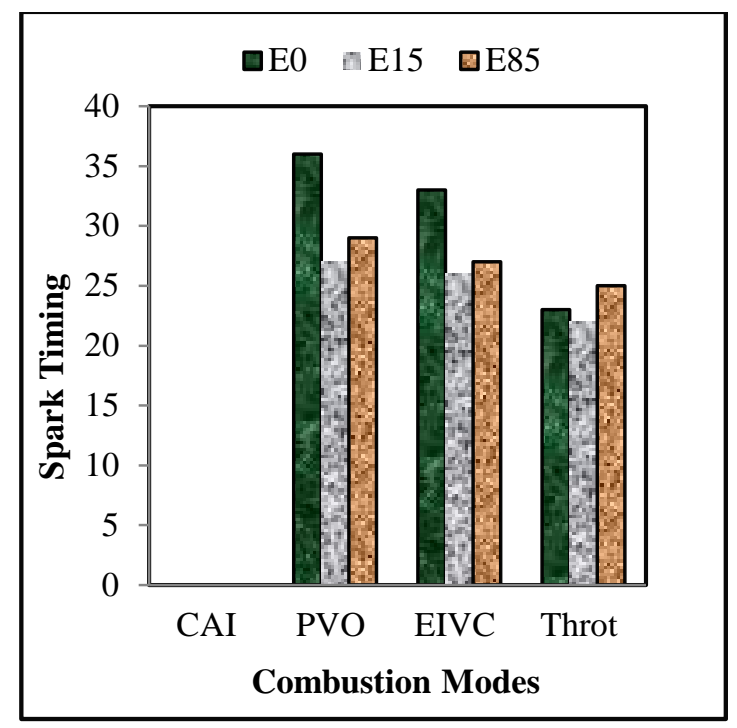

(b) Spark Timing (degCA BTDC)

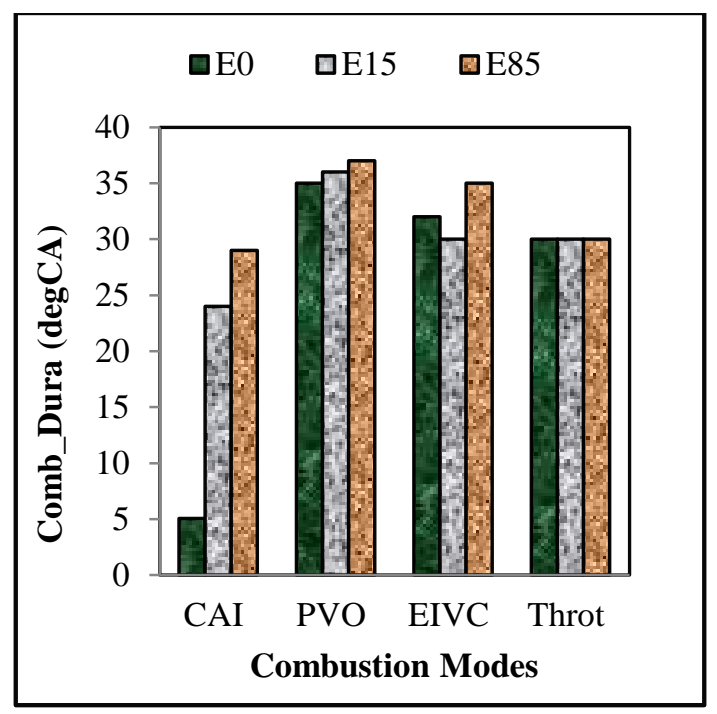

(d) Comb Duration (degCA ATDC)

Figure 6 Combustion Analysis 


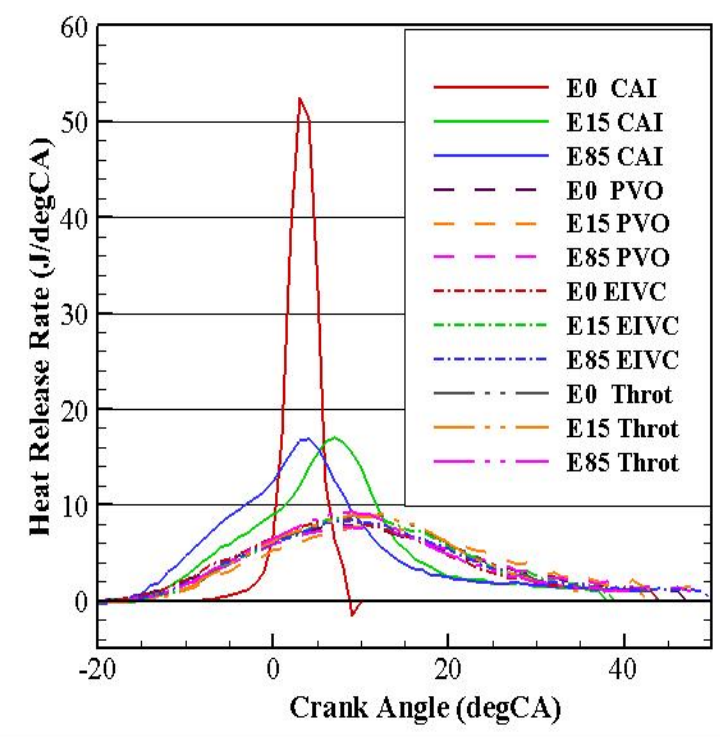

(e) Heat Release Rate

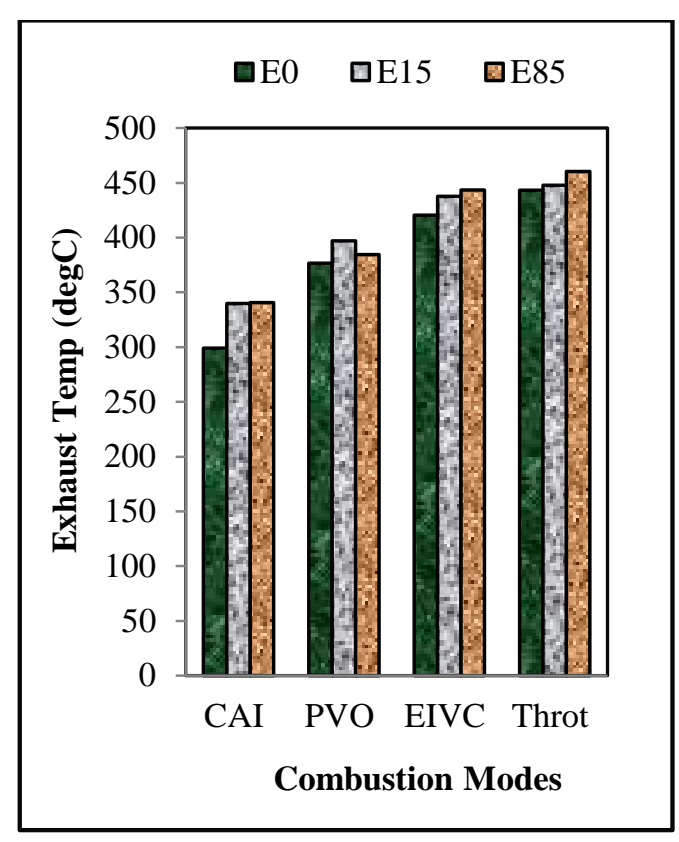

(f) Exhaust Temperature

\section{Figure 6 (contd) Combustion Analysis}

\section{Engine Performance and Efficiency Analysis}

The combustion efficiency is the ratio of heat liberated (QhrMEP) to the theoretical heat in the fuel (FuelMEP). The amount of heat liberated is less than the theotretical value because of incomplete combustion of hydrocarbon (HC) and carbon monoxide (CO) emissions. Therefore, the combustion efficiency can be calculated with good accuracy from the exhaust gas analysis as:

$\eta_{\text {comb }}=\left(1-\frac{\left(G_{C O} \times 10.1+G_{H C} \times 43\right)}{(\text { Fuel Flow rate } \times L H V)}\right)$

Where

G_CO, CO emission mass flow rate $(\mathrm{g} / \mathrm{h})$

G_HC, HC emission mass flow rate $(\mathrm{g} / \mathrm{h})$

$\mathrm{LHV}$, Lower heat values of the fuel $(\mathrm{MJ} / \mathrm{Kg})$

Figure 7(a) shows the combustion efficiency for all combustion modes and fuel blends. It can be seen that all but PVO operations suffered from less complete combustion with increasing ethanol content. This was mainly caused by the higher charge cooling effect of ethanol during the fuel injection process. In addition, the longer injection duration of ethanol injection could lead to poor mixture formation as evidenced by the higher CO emissions in Figure 8(a).

The combustion efficiency of the EIVC operation was lower than the throttled SI operations. This could have been caused by the different mixture formation process in EIVC. Althrough the reduced valve lift could have resulted in higher gas velocity past the valves, this 
improves the fuel atomisation process but the early closure of the intake valves would have further led to a cooler in-cylinder temperature.

In Figure 7a the CAI combustion shows the highest combustion efficiency with E15 which is same as for E0 which is below 95\%. This could be a result of the interaction of fuel injection and gas-exchange process. In the case of CAI, fuel was injected before TDC during the exhaust stroke when the in-cylinder charge temperature was much higher, whilst fuel was injected into cooler charge during the intake stroke in the throttled SI and EIVC combustion modes. Furthermore, there was more time for the fuel to mix with the air in the CAI mode. As a result, the mixture in the CAI combustion was likely to have been more homogenous than that in the throttled SI and EIVC combustion modes.

In contrast to the previous cases, the PVO combustion efficiency increased with the content of ethanol. This could be a result of the interaction between fuel injection and gas-exchange process it is characterised by the reversed flow of hot burned gas into the intake port during the positive overlap period around TDC. Fuel injection took place soon after the EVC during which the exhaust gas in the intake port flowed back into the cylinder together with air. As a result, fuel was injected into the hot incoming mixture. The enhanced evaporation of gasoline and its ethanol blend fuel led to fewer fuel rich regions in the combustion process and hence the reduced $\mathrm{CO}$ and $\mathrm{HC}$ emissions (Figure 8(a) and (b)).

The thermal efficiency of the engine is shown in Figure 7(b), which defines the upper limit of the efficiency obtainable from the engine and is calculated from the ratio of IMEPgross to the heat liberated (QhrMEP).

$$
\eta_{\text {therm }}=\left(\frac{I M E P_{\text {gross }}}{Q_{h r} M E P}\right)
$$

Where

$$
\begin{aligned}
& Q_{h r} M E P=\left(\frac{\text { Fuel Flow Rate } \times \text { LHV }}{V_{s} \times \text { Combustion Efficiency }}\right) \\
& I M E P_{\text {gross }}=\int_{-180}^{180} \frac{P}{V s} \dot{V}(\varphi) d \varphi
\end{aligned}
$$

Where Vs is the displacement of the engine

The thermal efficiency of the untrottled combustion modes display an increase in using E15 blend compared to the throttled SI. However, the PVO combustion shows highest thermal efficiency in all the blends, increasing from E0 blend to E85. This difference is likely to be due to the gas exchange process in PVO, as explained in combustion efficiency earlier.

The indicated engine efficiency $\left(\eta_{\text {ind }}\right)$ represents how efficiently the fuel energy is converted into indicated work. This quantity combines the effects of combustion duration, combustion phasing, combustion efficiency, and thermal efficiency on the high-pressure portion of the cycle, and is calculated from the ratio of the net work of the cycle to the heat released from the combustion process as: 
$\eta_{\text {ind }}=\left(\frac{I M E P_{n e t}}{Q_{h r} M E P}\right)$

Where

$I M E P_{\text {net }}=\int_{-180}^{540} \frac{P}{V S} \dot{V}(\varphi) d \varphi$

$P M E P=I M E P_{\text {net }}-I M E P_{\text {gross }}$

$\eta_{\text {GasExch }}=\frac{I M E P_{\text {gross }}}{I M E P_{\text {net }}}$

As shown in Figure 7(c), the gasoline CAI and PVO operations displayed the highest indicated efficiency due to the lack of pumping loss. The lower indicated efficiency of EIVC was associated with the throttling loss of intake flow through the smaller valve lift.

The throttled SI indicated efficiency shows a decreasing trend from 33\% with E0 to 31\% with E15 and E85. This decrease in indicated thermal efficiency may be due to the combustion process being deteriorated by the low in-cylinder temperature that results from the overcooling effects of the ethanol fuel. The indicated efficiency remained fairly constant during the EIVC and CAI operations. The CAI operation resulted in about 3\% higher indicated efficiency than the throttled SI and EIVC SI operations with a corresponding fuel savings of $10 \%$ (Figure 8(d)), which may be due to lower ISFC shown in Figure 8(d) as well as higher gas exchange efficiency shown in Figure 7(d).

The PVO SI shows an increasing trend in indicated efficiency of $35.6 \%$ with E0 to $40 \%$ with E85, which is about 1\% higher with E15 and 4\% with E85 than the baseline throttled operation which correspond to fuel savings of $8 \%$ and $22 \%$ as shown in Figure 8(d).

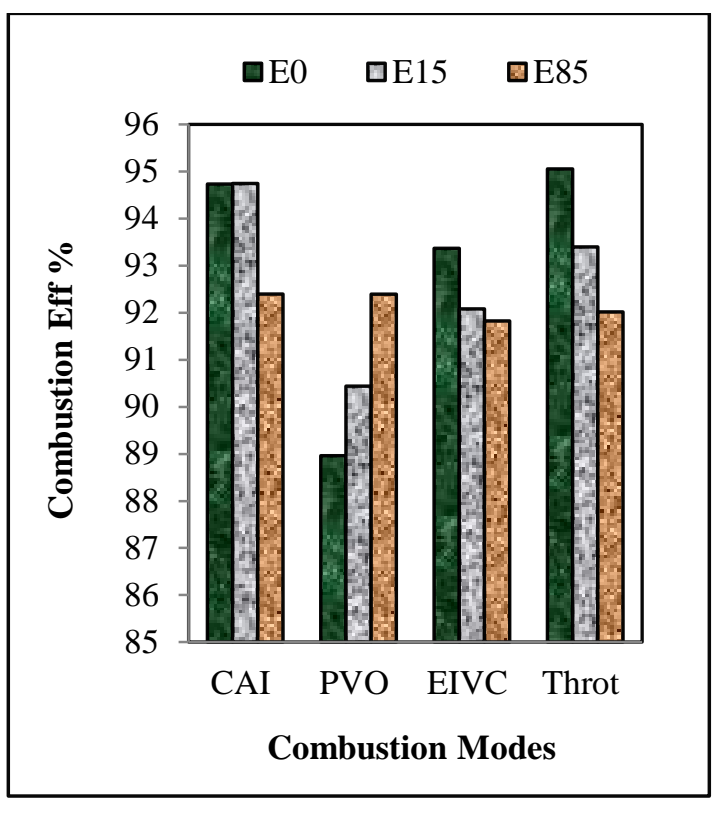

(a) Combustion Efficiency

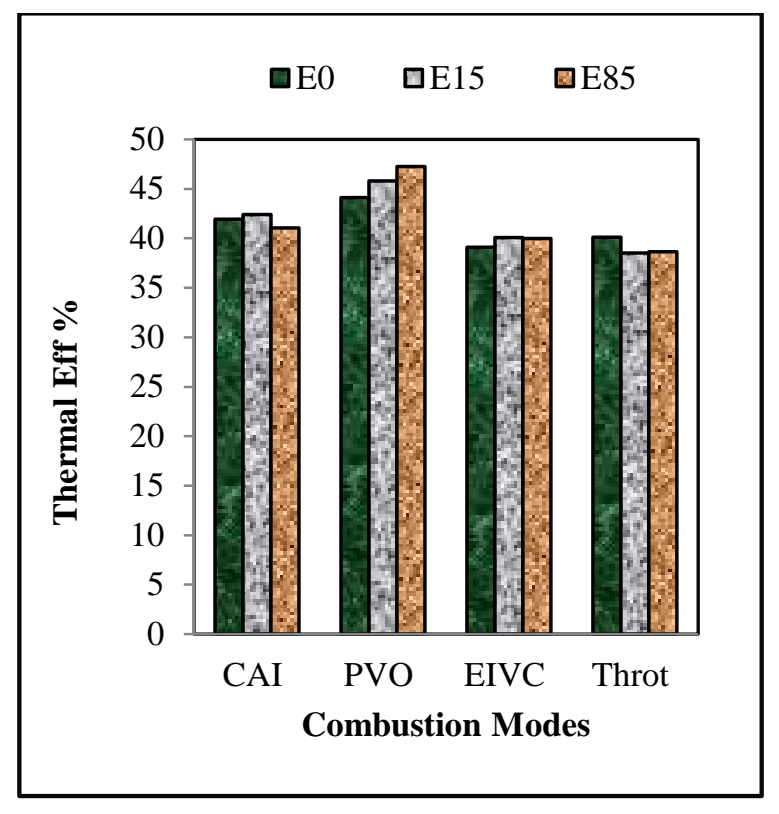

(b) Thermal Efficiency

Figure 7 Performance Analysis 


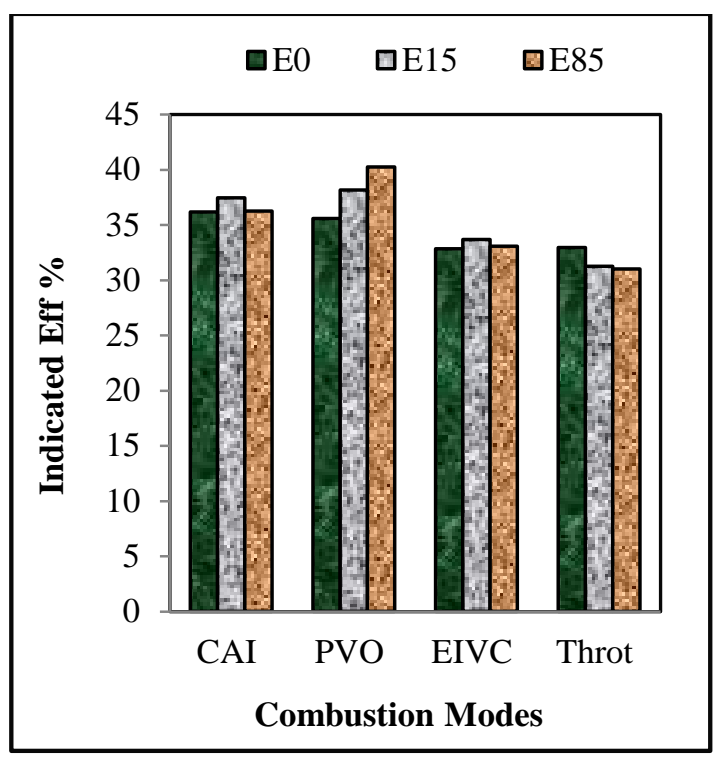

(c) Indicated Efficiency

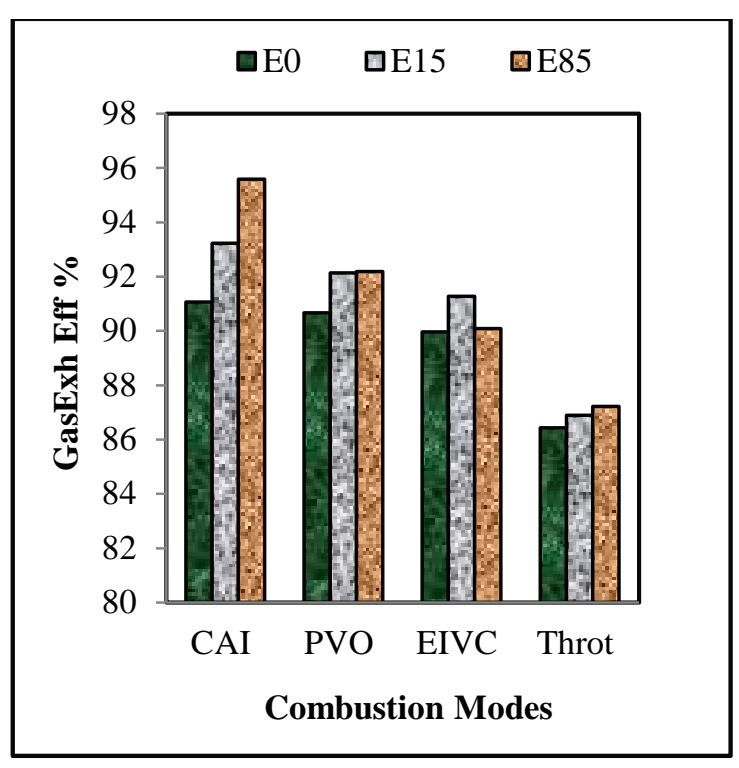

(d) Gas Exchange Efficiency

\section{Figure 7 (contd) Performance Analysis}

\section{Gaseous Emissions and Fuel Consumption Analysis}

In this part of the analysis, the exhaust emissions such as $\mathrm{CO}, \mathrm{HC}$, and NOx were analysed for the four combustion modes and the different fuel blends. All emissions results were converted to the indicated specific values (g/KWh).

Figure 8(a) shows the CO emission for the throttled SI, EIVC, PVO and the CAI combustion modes and fuel blends. The $\mathrm{CO}$ is one of the important emissions formed during combustion process depending on the local air to fuel ratio and the combustion temperature. As seen in Figure 8(a), the ISCO was lowest in CAI combustion in all the fuel blends. The highest CO was recorded during the PVO operation when gasoline fuel was used. With E15 and E85, the highest CO was recorded in the EIVC mode.

In both throttled SI and EIVC operations, the CO emission increased by a few times by using ethanol blended fuel. As discussed previously, such an increase may be caused by poor ethanol fuel mixture quality, the wall-wetting effect and low in-cylinder temperature as the percentage of ethanol fuel blend increased from E0 to E85.

In the case of the PVO mode, the CO emission decreased from 30.0g/KWh with E0 to 16.0g/KWh with E15 then decreased to 10.0g/KWh with E85. Overall PVO combustion resulted in $70 \%$ less CO emission than the throttled SI when E85 was used, then decreasing to about $20 \%$ with E15. As discussed in the previous section, when fuel injection took place early in the intake stroke into hot incoming residuals during the PVO mode operation, it resulted in better fuel evaporation and more complete mixing due to higher charge temperature. This helped to eliminate regions of rich mixture that were responsible for increased CO formations. 
In CAI combustion CO emission slightly decreased from $6.0 \mathrm{~g} / \mathrm{KWh}$ with E0 to $5.7 \mathrm{~g} / \mathrm{KWh}$ with E15 then increased to 8.9g/KWh with E85. Overall CO emission in the CAI mode was about 71\% lower than the throttled SI with E85 and E15, then decreasing to about 6\% with E0. As discussed in the previous section, when fuel injection took place early in the intake stroke into hot residuals during the CAI mode operation, it resulted in better fuel evaporation and more complete mixing due to higher charge temperature. This helped to eliminate regions of rich mixture that were responsible for increased $\mathrm{CO}$ formations

The HC emissions are significantly affected by mixture formation and the burned gas temperature. As shown in Figure 8(b), HC emission is much less sensitive to the fuel composition than CO emissions in both the EIVC mode and throttled SI mode. The PVO exhibited the most pronounced change in ISHC with ethanol content. It appeared that a more complete fuel evaporation had taken place with the E85.

It can be seen from Figure 8(c) that the CAI mode produced the lowest NOx emission as a result of the internal exhaust gas recirculation and the reduced combustion temperature (Figure 6(f)).

The fuel consumption were low in using E0 and E15 compared to E85 in all the combustion modes. However, the lowest fuel consumption was recorded for the PVO SI and the CAI combustion process shown in Figure 8(d). This may be as a result of the gas exchange in the PVO SI and the CAI combustion process as explained earlier. The highest fuel consumption was recorded in the EIVC and the throttled SI combustion process in using E85. The result in throttled SI may likely be as a result of the pumping loss in part load operation.

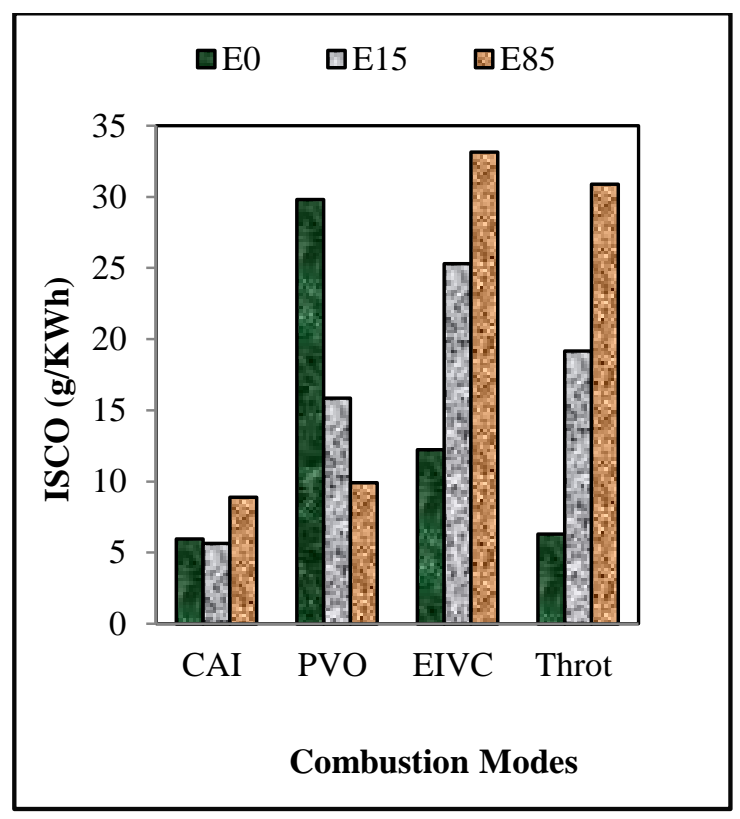

(a) ISCO

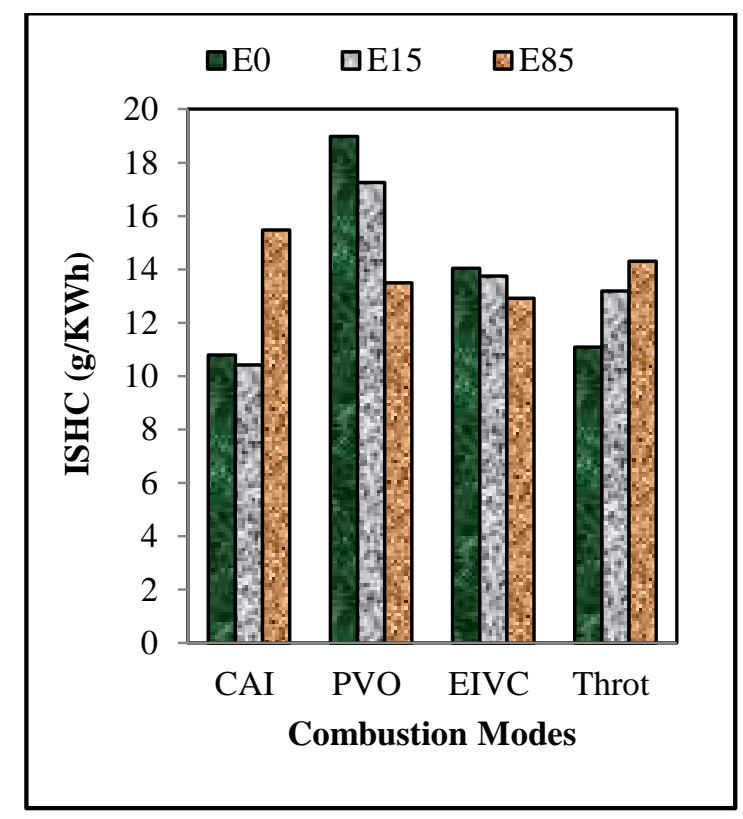

(b) ISHC

Figure 8 CO, HC, NOx Emissions and Specific Fuel Consumption 


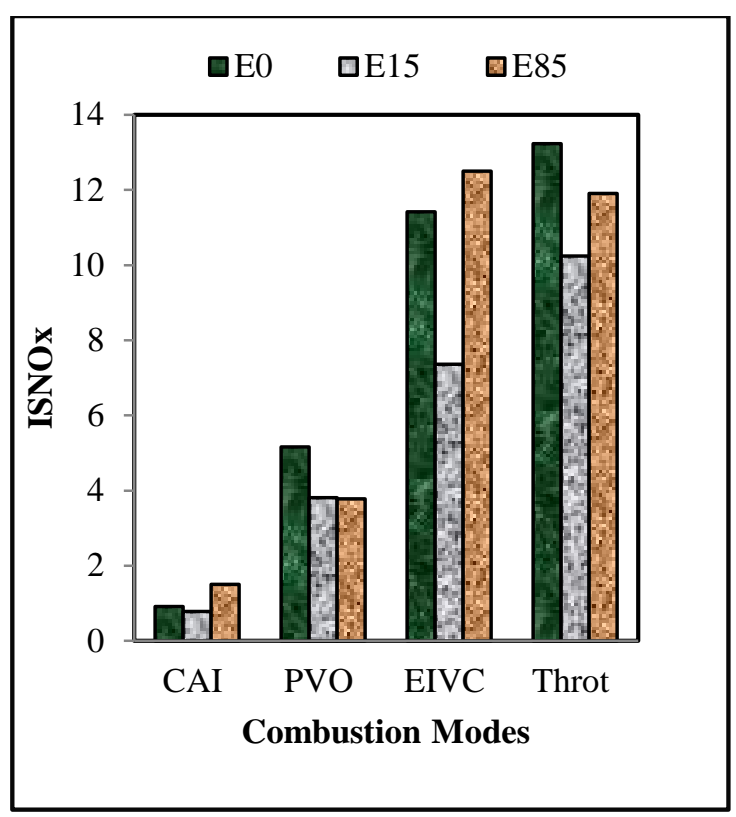

(c) ISNOx

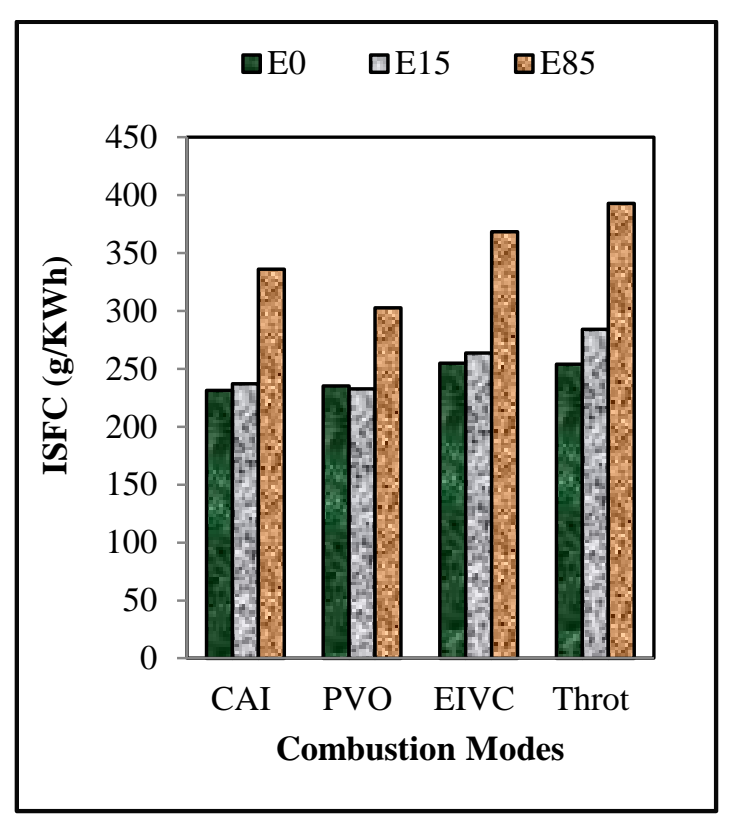

(d) ISFC

Figure 8 (contd) CO, HC, NOx Emissions and Specific Fuel Consumption

\section{Particulate Emissions}

The particulate emissions were measured and analyzed in their total numbers and size distributions. Figure 9(a) shows that the total number of particles varies between different operational modes and the effect of ethanol on particle numbers is also mode dependent. In the case of throttled SI operations, the number of particles decreased rapidly when the ethanol content was increased from zero to 85\%. As shown in Figure 9(b), the majority of particles were around $20 \mathrm{~nm}$ in diameter. As it is generally accepted that the smallest particles are mainly condensates and that the larger particles are soot particles. The appearance of peaks in the number of particles of around 20nm with gasoline suggests that soot particle of this size were formed and emitted under such operating conditions. The presence of oxygen in E15 and E85 helped to reduce the soot formation.

In the case of EIVC, Figure 9(a) shows that E85 resulted in significant rise in the total particle numbers, which was dominated by particles of diameter between $15-20 \mathrm{~nm}$ as shown in Figure 9(b). This may be explained by the valve-timing and fuel-injection-timing diagram in Figure 3. Because of its lower calorific value, a larger volume of E85 was injected over a longer duration and most of E85 was injected after IVC when the charge temperature was reduced with expansion in the second half of the intake stroke. Furthermore, the charge cooling effect of E85 was more pronounced in the case of EIVC as injection took place with a fixed intake mass. As a result, the E85 fuel injection took place in a cooler environment resulting in reduced evaporation.

The PVO mode was characterised by the lowest number of particles amongst the four operational modes. This is most likely to have been caused by the higher charge temperature of internally re-circulated burned gases. It shows that E85 reduced the soot particles but led to 
some increase in the smallest particles (Figure 9(b)) of condensates whilst E15 produced more particles of all sizes.

As shown in Figure 9(a), the CAI mode with pure gasoline E0 was characterised by the highest number of particles amongst the four operational modes. There are two plausible causes to the production of soot particles at greater numbers in the CAI combustion mode. In the case of CAI operation, fuel was injected into the hot burned gas at a high temperature but with little oxygen. This would cause hydrocarbons in gasoline to undergo thermochemical decomposition at elevated temperatures without the participation of oxygen, known as pyrolysis [33, 36], in which soot particles could be produced. Although most of such soot particles would have been oxidised during the combustion process, the lower combustion temperature in CAI mode (Figure 6(f)) rendered the soot oxidation process less effective. The presence of oxygen in E15 and E85 helped to reduce the particle formation by shifting the particle number towards smaller size particles shown in Figure 9(b).

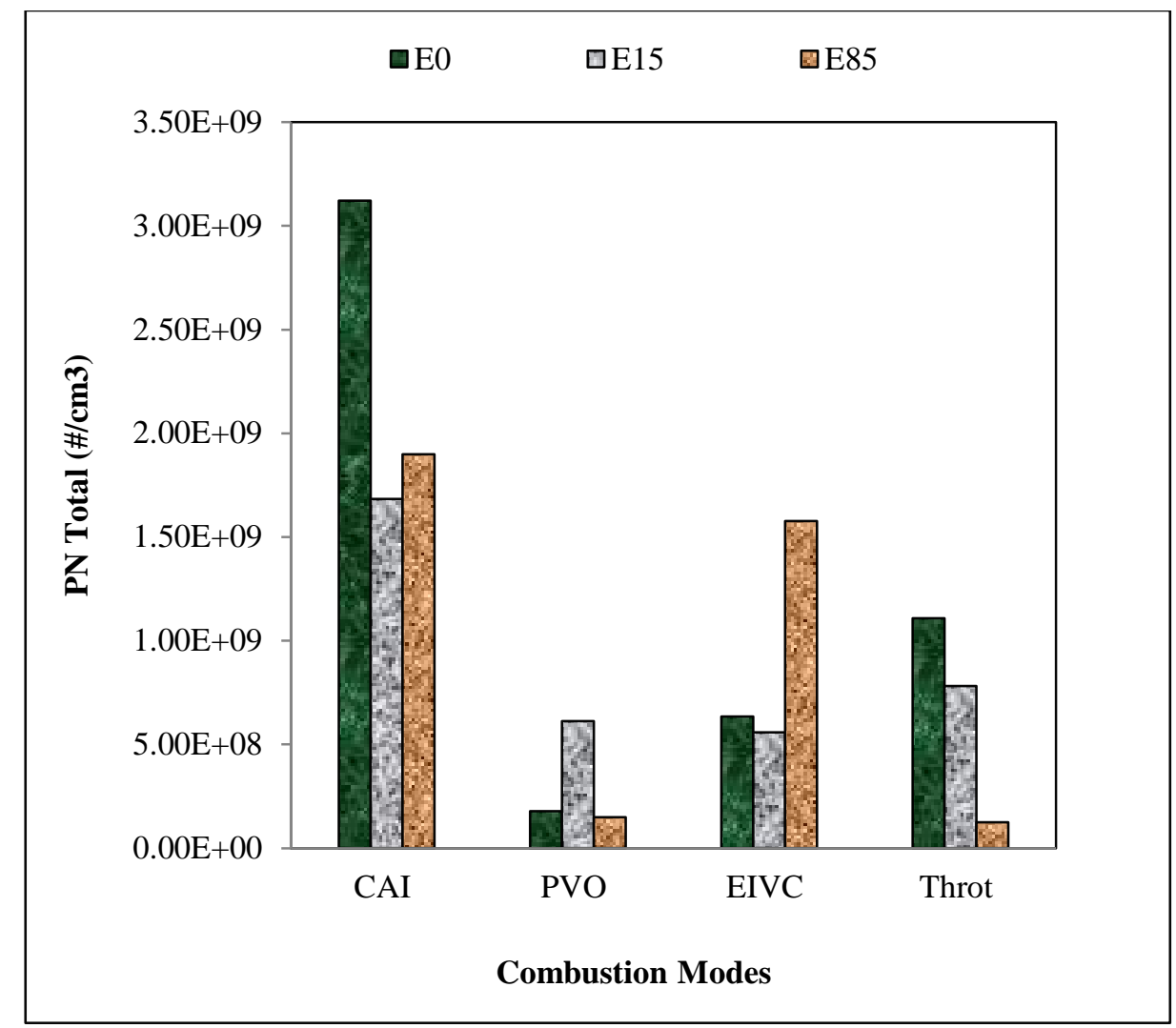

(a) Total Particulate Number Emission

\section{Figure 9 Particulate Emission}






\section{(b) Particulate Number Emission}

\section{Figure 9 (contd) Particulate Emission}

\section{Effects of Air to Fuel Ratio on Particulate Emissions}

Figure 10 shows that the effect of lambda on total particulate numbers (PN) is dependent on the combustion modes and fuel blends. The most pronounced reduction in PN by lean burn combustion is obtained in the CAI operation of gasoline. The leaner gasoline mixtures resulted in an increase in the total PN during the PVO operation but a slight reduction in PN in the EIVC mode. During the throttled SI operation, the total PN increased slightly and then fell as the gasoline mixture became leaner.

In the case of E15, all modes but the CAI mode exhibited slight reduction in the total PN as the mixture became leaner. With E85, the total PN was increased above the stoichiometric mixture, probably due to the reduced oxidation rate at lower combustion temperature with the leaner mixture. 


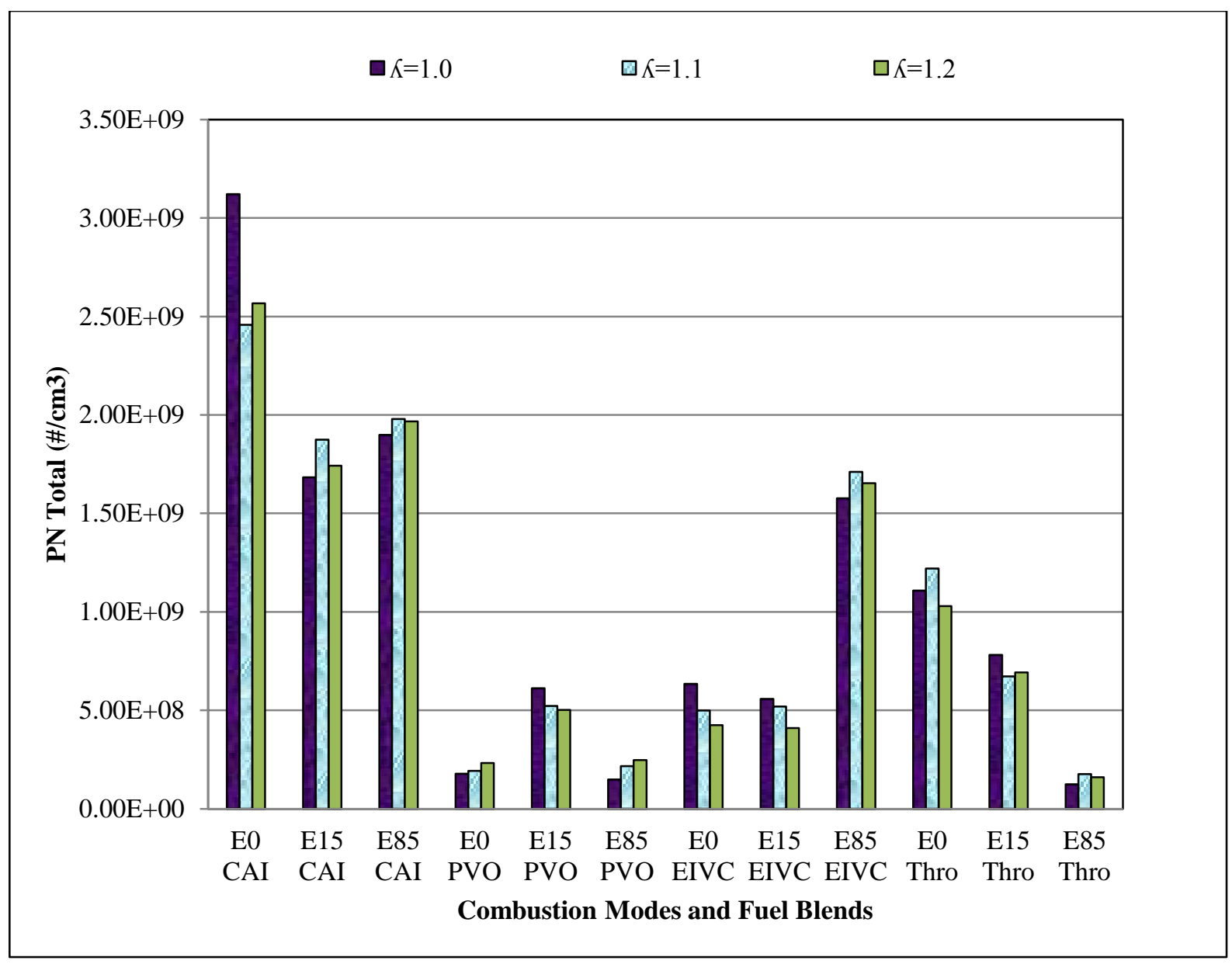

Figure 10 Lambda effects on Particulate Emission

\section{Summary and Conclusion}

The effects of combustion modes and ethanol content on the combustion and fuel conversion efficiencies, gaseous emissions, particulate number and size distributions were studied in the same single-cylinder direct-injection engine. The results obtained from the same engine eliminate the ambiguity associated with different engine designs. The main findings can be summarised as follows:

1. Of the four operational modes, at 3.2bar IMEP load condition, and 1500rpm, the throttled SI was characterized by the lowest gas-exchange efficiency and fuel economy. The particle emissions from the direct injection engine were dominated by smaller particles characterised by a peak of between $10 \mathrm{~nm}$ to $30 \mathrm{~nm}$ in diameter. In the throttled SI mode, the presence of ethanol led to a significant reduction in the formation and emission of particulates.

2. The EIVC mode resulted in slower combustion than the throttled SI mode due to lower turbulence. The EIVC mode was characterised by the low number of particulates in using E0 and E15 compared to the throttled SI mode. The addition of 
ethanol caused a significant increase in CO emissions from locally rich mixtures due to increased injection durations during the EIVC combustion.

3. The PVO mode was characterized by the lowest ISFC in using E15 and E85 resulting in $8 \%$ and $22 \%$ improvement in fuel consumption. The PVO suffered from the lowest combustion efficiency but the higest thermal and indicated efficiencies, and the lowest ISFC. The addition of ethanol had the most pronounced effect on improving combustion efficency in the PVO mode. The PVO mode was characterised by the lowest number of particles amongst the four operational modes because of the higher in-cylinder charge temperature. The effect of ethanol was the least evident on particle emission.

4. The CAI mode was characterized by the shortest combustion duration, due to the simultaneous burning of the mixture. Gasoline CAI operation has the lowest ISFC. The addition of ethanol had the most pronounced effect on reducing the pressure-rise rate of CAI combustion mode. The CAI mode produced the least NOx and CO in all the fuel blends, and the least HC emissions in using E0 and E15.

5. The CAI mode emitted the highest number of particulates, the fuel injection during the NVO period was assumed to lead to the production of soot particles $(<50 \mathrm{~nm}$ in size) in the CAI combustion mode due to hydrocarbon pyrolysis. The soot oxidation was rendered less effective by the lower combustion temperature. The presence of ethanol led to a reduction in number of particulate emitted in CAI combustion because of the nature of ethanol to oxygenates.

The results were obtained with a production DI injector that is limited to 100bar injection pressure and single injection. Further improvement in fuel consumption and particulate emission could be obtained by higher injection pressure and multiple injections and combustion chamber design, which will be accomplished by the installation of a new injector and new piston.

\section{References}

1. Flierl R. and Kluting M. "The Third Generation of Valvetrains-New Fully Variable Valvetrains for Throttle-Free Load Control”. SAE Technical Paper 2000-01-1227.

2. Kreuter, P., Heuser, P., and Schebitz, M. "Strategies to Improve SI-Engine performance by means of variable Intake lift, Timing and Duration”. SAE Technical Paper 920449, 1992.

3. Vogel, O., Roussopoulos, K., Guzella, L. and Czekaj, J. "Variable Valve Timing Implemented with a Secondary valve on a four cylinder SI engine," SAE Technical Paper 970335, 1997. 
4. Soderberg, F., and Johansson, B. "Fluid Flow, Combustion and Efficiency with Early or Late Inlet Valve Closing”. SAE Technical Paper 972937, 1997.

5. Urata, Y., Umiyama, H., Shimizu, K., Fujiyoshi, Y., Sono Hiroshi., and Fukuo, K. “A Study of Vehicle Equipped with Non-Throttling S.I. Engine with Early Intake Valve Closing Mechanism”. SAE Technical Paper 930820, 1993.

6. Patel, R., Ladommatos, N., et al. "Comparison between Unthrottled, Single and Two-valve induction Strategies Utilising Direct gasoline Injection: Emissions, Heat-release and Fuel Consumption Analysis”. SAE Technical Paper 2008-01-1626,2008.

7. Zhao H. "HCCI and CAI engines for the automotive industry", Woodhead Publishing, Cambridge, 2007

8. Onishi, S., et al. "Active Thermo-atmosphere Combustion (ATAC) a new combustion process for internal combustion engines". SAE Technical Paper 790501, 1979.

9. Allen Jeff., and Law Don. "Variable Valve Actuated Controlled Auto-Ignition: Speed Load Maps and Strategic Regimes of Operation". SAE Technical Paper 2002-01-0422

10. Koopmans Lucien., and Ingemar Denbratt. "A Four Stroke Camless Engine, Operated in HCCI Mode with commercial gasoline". SAE Technical Paper 2001-01-3610, 2001.

11. Zhao, H., et al. "Control strategies for steady and transient operation of a 4-stroke gasoline engine with CAI combustion using a 4-variable valve actuating system (4VVAS)". SAE Technical Paper 2006-01-1083, 2006.

12. Wolters, p., et al. "Controlled auto ignition combustion process with electromechanical valve train". SAE Technical Paper 2003-01-0032, 2003.

13. Claus, B., and Dietmar, S. "VarioCam Plus - A Highlight of te Porsche 911 Turbo Engine”. SAE Technical Paper 2001-01-0245, 2001.

14. Sellnau, M., and Rask, E. "Two-Step Variable Valve Actuation for Fuel Economy, Emissions, and performances”. SAE Technical Paper 2003-01-0029, 2003.

15. Flierl, R., and Kluting, M. "The Third Generation of Valvetrains - New Fully Variable Valvetrains for Throttle-Free Lod Control”. SAE Technical Paper 2000-01-1227, 2000.

16. Theobald, M A., Lequesne, B., and Henry, R. "Control of Engine Load via Electromagnetic Valve Actuators”. SAE Technical Paper 94081, 1994.

17. Wu, H., Chen, J., Li, M., Durret. R. et al. "Iterative Learning Control for a Fully Flexible Valve actuation in a test cell”. SAE Int. J. Engines 6(1):2012, doi:10.4271/2012-01-0162, 2012. 
18. Postrioti, L., Battistoni, M., Foschini, L., and Flora, R. "Application of a Fully Flexible electro-Hydraulic Camless system to a Research SI Engine”. SAE Technical Paper 2009-010075, 2009.

19. Sturman, O. “Hydraulic Actuator for an Internal Combustion Engine”. U.S. Patent 5638 781, 1994.

20. Schetcner, M. M., and Levin, B. M. “Camless Engine,” SAE Technical Paper 960591, 1996.

21. Jeff Allen., and Don Law. "Production Electro-Hydraulic Variable valve-train for a New Generation of I.C. Engines”. SAE Technical Paper 2002-01-1109, 2002.

22. Kreuter, P., Heuser, P., and Joachim, R-M. "The Meta VVH System - A continuously Variable valve timing system”. SAE Technical Paper 980765, 1998.

23. Kreuter, P., Heuser, P., et al. "Variable Valve Actuation - Switchable and Continuously Variable Valve Lifts”. SAE Technical Paper 2003-01-0026, 2003.

24. Tai, C., Tsu-Chin, T., et al. "Using Camless Valvetrain for air Hybrid Optimisation”. SAE Technical Paper 2003-01-0038, 2003.

25. Price P., Stone R., Misztal J., et al. "Particulate emissions from a gasoline Homogeneous Charge Compression Ignition Engine”. SAE Technical Paper 2007-01-0209, 2007.

26. Graskow B R., Kittelson D B., Ahmadi M R and Morris J E. "Exhaust Particulate Emissions from a Direct Injection spark ignition Engine”. SAE Technical Paper 1999-011145, 1999.

27. Maricq M., Podsiadlik D., Brehob D. and Mohammad Haghgooie M. "Partculate emissions from a Direct-Injection Spark-Ignition (DISI) Engine”. SAE Technical Paper 1999-01-1530, 1999.

28. Dimou I., Kar K. and Cheng W. "Particulate Matter Emissions from a Direct Injection Spark Ignition Engine under Cold Fast Idle Conditions for Ethanol-Gasoline Blends”. SAE Technical Paper 2011-01-1305, 2011.

29. DeCarlo P F., Slowik J G., Worsnop D R., Davidotis P. and Jimenez J L. "Particle Morphology and Density Characterisation by Combined Mobility and Aerodynamic Diameter Measurements. Part 1: Theory”. Aerosol Sci. Technol.38: 2004.

30. Slowik J G., Stainken K., Davidovits P., Williams L R., Jayne J T., Kolb C E., Worsnop D R., Rudich Y., DeCarlo P F and Jimenez J L. "Particle Morphology and Density Characterisation by Combined Mobility and Aerodynamic Diameter Measurements. Part 2: Application to Combustion Generated Soot Aerosols as a function of Fuel Equivalence Ratio”. Aerosol Sci.Technol.38: 2004.

31. Khalek I A., Bougher T and Jetter J J. “ Particle Emissions from a 2009 Gasoline Direct Injection Engine Using Different Commercially Available Fuels”. SAE Technical Paper 2010-01-2117, 2010. 
32. Hedge M., Weber P., Gingrich J., Alger T and Khalek I. "Effect of EGR on Particle Emissions from a GDI Engine”. SAE Technical Paper 2011-01-0636, 2011.

33. Kittleson D B. "Engines and Nanoparticles: A Review”. J. Aerosol Sci. Vol. 29. No. 5/6., 1998.

34. Ojapah M M, Zhang Y, and Zhao H. "Effects of Ethanol on Performance and Exhaust Emissions from a DI Spark Ignition Engine with Throttled and Unthrottled Operations". SAE Technical Paper 2014-01-1393, 2014.

35. Ojapah M M, Zhang Y, and Zhao H. "Effects of Ethanol on Part-load Performance and Emissions Analysis of SI Combustion with EIVC and Throttled Operation and CAI Combustion". SAE Technical Paper 2014-01-1611, 2014

36.Eastwood P. "Particulate Emissions from Vehicles”. 2008

\section{CONTACT INFORMATION}

Mohammed Moore Ojapah: mohammed.ojapah@uniport.edu.ng

\section{ACKNOWLEDGMENTS}

The authors would like to acknowledge the financial support to Dr Ojapah to carry out his PhD studies at Brunel University by the Tertiary Education Trust Fund of Nigeria Government and University of Portharcourt Nigeria.

\section{ABBREVIATIONS}

$\begin{array}{ll}\text { 4str } & \text { 4-stroke } \\ \text { 2str } & \text { 2-stroke } \\ \text { AC } & \text { Alternating current } \\ \text { ATDC } & \text { After top dead centre } \\ \text { AVT } & \text { Active valve train } \\ \text { BDC } & \text { Bottom dead centre } \\ \text { BMEP } & \text { Brake mean effective pressure } \\ \text { BSFC } & \text { Brake specific fuel consumption } \\ \text { CA } & \text { Crank angle } \\ \text { CA50 } & \text { 50\% mass fuel burnt crank angle } \\ \text { CAI } & \text { Controlled auto ignition } \\ \text { DMA } & \text { Differential mobility analyser } \\ \text { E0 } & \text { Pure gasoline } \\ \text { E15 } & \text { 15\% ethanol blend } \\ \text { E85 } & \text { 85\% ethanol blend } \\ \text { EGR } & \text { Exhaust gas recirculation } \\ \text { EIVC } & \text { Early intake valve closure } \\ \text { EMS } & \text { Electrostatic mobility spectrometer } \\ \text { EVC } & \text { Exhaust valve closed }\end{array}$




$\begin{array}{ll}\text { EVO } & \text { Exhaust valve open } \\ \text { FCE } & \text { Faraday cup electrometer } \\ \text { FFVVA } & \text { Fully flexible variable valve actuation } \\ \text { FMEP } & \text { Friction mean effective pressure } \\ \text { GDI } & \text { Gasoline direct injection } \\ \text { HCCI } & \text { Homogeneous charge compression ignition } \\ \text { IEGR } & \text { Internal exhaust gas recirculation } \\ \text { IMEP_net } & \text { Net indicated mean effective pressure } \\ \text { ISCO } & \text { Indicated specific carbon monoxide } \\ \text { ISFC } & \text { Indicated specific fuel consumption } \\ \text { ISHC } & \text { Indicated specific hydro carbon } \\ \text { ISNOx } & \text { Indicated specific NOx } \\ \text { IVC } & \text { Intake valve close } \\ \text { IVL } & \text { Intake valve lift } \\ \text { IVO } & \text { Intake valve open } \\ \text { LHV } & \text { Lower heating value of fuel } \\ \text { MBT } & \text { Minimum ignition advance for best torque } \\ \text { NVO } & \text { Negative valve overlap } \\ \text { P } & \text { Cylinder pressure } \\ \text { PM } & \text { Particulate matter } \\ \text { PN } & \text { Particulate number } \\ \text { PMEP } & \text { Pumping mean effective pressure } \\ \text { PVO } & \text { Positive valve overlap } \\ \text { Qhr } & \text { Heat release rate } \\ \text { RON } & \text { Research octane number } \\ \text { SI } & \text { Spark ignition } \\ \text { TDC } & \text { Top dead centre } \\ \text { THC } & \text { Total unburnt hydrocarbon } \\ \text { Throt } & \text { Throttle } \\ \text { Vs } & \text { Engine displacement volume } \\ \text { VVT } & \text { Variable valve timing } \\ \text { WOT } & \text { Wide open throttle } \\ \varphi & \text { Crank angle } \\ \eta & \text { Efficiency } \\ & \end{array}$

